or four times a week. But, in addition to the problems that a transplant operation presents to any patient, children are liable to suffer serious impairment of growth. They often remain short. ${ }^{12} \mathrm{~A}$ useful report has been published recently from Los Angeles on this problem.

C. M. Grushkin and R. N. Fine ${ }^{3}$ report on the growth of 26 children who have survived at least one to four years after a kidney transplant. The patients were aged $1 \frac{1}{2}$ to 17 , and most of them had cadaver grafts. Only six of the 26 achieved a normal linear growth rate, and a further five had some useful growth at about half the normal rate. These figures sound more depressing than they really are because many of the children were rather old at the time of the transplant. In those who had a bone age of under 12 years and whose distal femoral and proximal tibial epiphyses had not fused by the time of transplant $40 \%$ achieved normal growth and $30 \%$ useful growth subsequently. The Los Angeles workers concluded that the most critical factor in predicting whether or not growth would occur after transplant was a bone age of less than 12 years.

An important cause of the poor growth is likely to be the immunosuppression that is required after a transplant. In Europe extensive use is made of kidneys from the child's parent. Even so most of the recipients need large doses of corticosteroids to prevent graft rejection. If a child receives more than $10 \mathrm{mg}$ of prednisone per square metre of body surface per day, growth is likely to be suppressed (a 9-yearold has a surface area of about $1 \mathrm{~m}^{2}$ ). Treatment on alternate days interferes less with growth, ${ }^{4}$ but it is not yet certain that it provides satisfacory immunosuppression. ${ }^{5}$ Steroids are certainly not the only factor adversely affecting growth in children who have had transplants. In fact many problems remain unsolved. Boys tend to grow better than girls after a transplant and there are isolated examples of children on very large doses of steroids who have grown better than others receiving small doses. ${ }^{3}$

Naturally the poor growth of some children after renal transplantation has to be considered in the context of their life without the operation and the best age to have it. Children with renal failure grow poorly, and if they develop renal osteodystrophy they may become severely deformed and stunted. With regular haemodialysis they will grow and mature, but in many the growth is less than normal, ${ }^{6}$ and it is not completely clear whether this is related to inadequate food intake, insufficient dialysis, or other factors arising from their primary kidney disease. The parents of children with renal failure and the doctors advising them have a difficult choice to make. At present centres in the United Kingdom are concentrating their resources on children over the age of $5 .^{2}$ For the young school child many people would advise sereral years of regular haemodialysis (in the home) before embarking on transplantation. This seems reasonable, since the growth problems on dialysis are usually less than those following transplantation. But if either haemodialysis or the child's growth while receiving it is unsatisfactory, then it seems best to do the transplant before the child reaches the age of 12-14 in order to take the chance of a period of active growth before the epiphyses fuse.

1 Potter, D., et al., Pediatrics, 1970, 45, 432.

2 Lilly, J. R., et al., Pediatrics, 1971, 47, 548.

3 Grushkin, C. M., and Fine, R. N., American fournal of Diseases of Children, 1973, 125, 514

Ney, R. L., Hospital Practice, 1968, 3, 57.

5 Reed, W. P., Lucas Z. J., and Cohn, R., Lancet, 1970, 1, 747.

- Baillod, R. A., Ku, G., and Moorhead, J. F., Proceedings of the European Dialysis and Transplant Association, 1972, 9, 335.

\section{Sir Rickard Christophers}

On 27 November Sir Rickard Christophers, F.R.S., attained the grand age of 100 . And with countless friends and admirers the B.M.F. congratulates him on receiving the gift of healthy old age to crown a remarkable career in tropical medicine. He is and will remain a legend in the Indian Medical Service and in the larger sphere of medical parasitology. Together with a versatile command of protozoology, entomology, and geology he had an administrative ability that is not always conspicuous in scientists but is of especial value in the tropics.

Christophers started his scientific career after graduating in medicine at Manchester by going with Professor J. W. Stephens, of Liverpool, to study blackwater fever in Africa under the auspices of the Royal Society. At that time the Punjab in India was suffering from devastating epidemics of malaria, and he was appointed to investigate the problem. In the event he carried out a pioneer study of these disastrous outbreaks and laid down a framework of investigation which is the basis of procedures still followed in malarial epidemiology. Among his early interests in India was the study of babesiosis (tick fever) in dogs. In this connexion, he made a detailed study of the anatomy of the transmitting vector, the tick Rhipicephalus sanguineus, and described many of the stages of the parasite found in it.

In 1916 Christophers became director of the Central Laboratory in Basra. The main study here was necessarily malaria, and he carried out an elaborate survey over the whole field of operations from the mouth of the Shatt-el-Arab to the mountains of Kurdistan and much of Persia. After the end of the first world war he was recalled to India to assume directorship of the Central Research Institute in Kasauli, the major medical research establishment in the country. While in this appointment he was elected to Fellowship of the Royal Society in 1926 and was later a recipient of the Society's Buchanan medal. About this time he was seconded as director of the newly founded Kala-azar Commission in Assam, where one of the devastating epidemics of this disease was then at its height. Here his entomological skill produced a beautifully detailed study of the anatomy of the transmitting agent, Phlebotomus argentipes, especially of the biting mouth parts.

On his retirement from India in 1931 his entomological interests resulted in a classical memoir on the mosquito Aedes aegypti. This is probably the most accurate and detailed histological study of any insect, and an essential work of reference, for which the techniques of dissection and microscopial section-cutting were entirely the personal work of the author. During the 1930s his work on malaria took a new turn at the London School of Hygiene and Tropical Medicine and subsequently at Cambridge, when he investigated the mode of action of antimalarial drugs and mosquito repellents. Nor was his far-ranging mind restricted to medicine only, for he was intensely interested in geology and palaeontology and never happier than when working with his geological hammer in the lower Himalayas and the rich fossil beds of the Siwalik Hills.

As a government servant suffice it to say that on all scientific matters Christophers was the final court of appeal and advice to the Indian Government, and his services were rewarded by the conferring of a knighthood. By his colleagues in the I.M.S. he is respected as one of the greatest members, and certainly the greatest living member, of the service he so brilliantly embellished. They recall too that throughout his career the late Lady Christophers was his essential partner and was as esteemed and loved as he is. 